Gerardo Aniano C. Dimaguila, MD, MPH

Nixon S. See, MD

Francisco A. Victoria, MD

Department of Otolaryngology Head and Neck Surgery

Ospital ng Maynila Medical Center
Correspondence: Dr. Gerardo Aniano C. Dimaguila Department of Otolaryngology- Head and Neck Surgery Ospital ng Maynila Medical Center

Quirino Ave. corner Roxas Blvd.

Malate, Manila 1004

Philippines

Phone: (+63) 5246061 Local 220

Fax: (+63) 5246065

Email:Ommc enthns@yahoo.com

Reprints will not be available from the author.

The authors declared that this represents original materia that is not being considered for publication or has not been published or accepted for publication elsewhere in full or in part, in print or electronic media; that the manuscript has been read and approved by all the authors, that the requirements for authorship have been met by each author, and that each author believes that the manuscript represents honest work.

Disclosures: The authors signed disclosures that there are no financial or other (including personal) relationships, intellectual passion, political or religious beliefs, and institutional affiliations that might lead to a conflict of interest.

\section{Surgical Management of Chronic Suppurative Otitis Media with Intracranial Complications}

Intracranial abscess is a serious, life-threatening condition with a dire prognosis. Although the advent of the antibiotic era has drastically reduced the incidence of the disease, predisposing factors such as untreated ear infections, poor personal hygiene, significant trauma with violation of the sterile cranial environment as well as existing co-morbidities such as an immunocompromised state make intracranial abscess a horrifying reality. Ear infections, in particular, are notorious for being the origin of roughly $50 \%$ of cerebellar abscesses. ${ }^{1}$

Chronic suppurative otitis media (CSOM) is one of the leading causes of brain abscess. Shaw and Russell ${ }^{2}$ reviewed 47 cases of cerebellar abscess and showed that $93 \%$ were caused by CSOM; the most common mechanism of entry into the brain parenchyma being direct extension. Chronic infection in the middle ear space could erode through the tegmen tympani and into the temporal lobe or through the tegmen mastoidei into the cerebellum. Neurological symptoms may be delayed as the abscess 'grows' in areas around the cerebellum that are regarded as 'silent', until vital areas such as those responsible for coordination and balance are violated.

We describe a case of cerebellar abscess secondary to CSOM and discuss the possibility of performing ear surgery with simultaneous drainage of a contiguous abscess through a transmastoid approach in cases of chronic suppurative otitis media with intracranial complications.

\section{CASE REPORT}

A 21-year-old man consulted with a chief complaint of headache. The history started 13 years prior to consult, when at the age of 8 , he developed ear pain with ear discharge. Since then, ear discharge recurred around 4-5 times a year despite various medications prescribed by different physicians. Each time, an ENT specialty consultation was advised but not availed of.

One month prior to admission, the patient consulted a physician for recurrent temporal headaches radiating to the periorbital area and described as sometimes crushing, sometimes throbbing, with VAS pain scale 5/10 and associated with nausea. There was also pain in both ears and purulent, foul smelling discharge from the left ear associated with decreased hearing. Unrecalled medications were again prescribed and he was sent home with an ENT specialist referral which he did not comply with.

Two weeks prior to admission, the headache grew worse, $8-9 / 10$ on the pain scale with persistent nausea and progressive hearing loss on the left ear despite the unrecalled medications.

One week prior to admission, the intolerable condition prompted an ENT specialist consult and diagnosis of chronic suppurative otitis media, AS and chronic otitis media, AD. Cefuroxime $500 \mathrm{mg}$ tab every 8 hours, celecoxib 200mg tab every 12 hours and ofloxacin otic drops every 8 hours were started and hospital admission was advised but initially refused. A temporal bone CT scan showed a large cholesteatoma with destruction of the posterior wall of the left mastoid and probable intracranial extension. (Figure 1) The patient then consented to admission. 


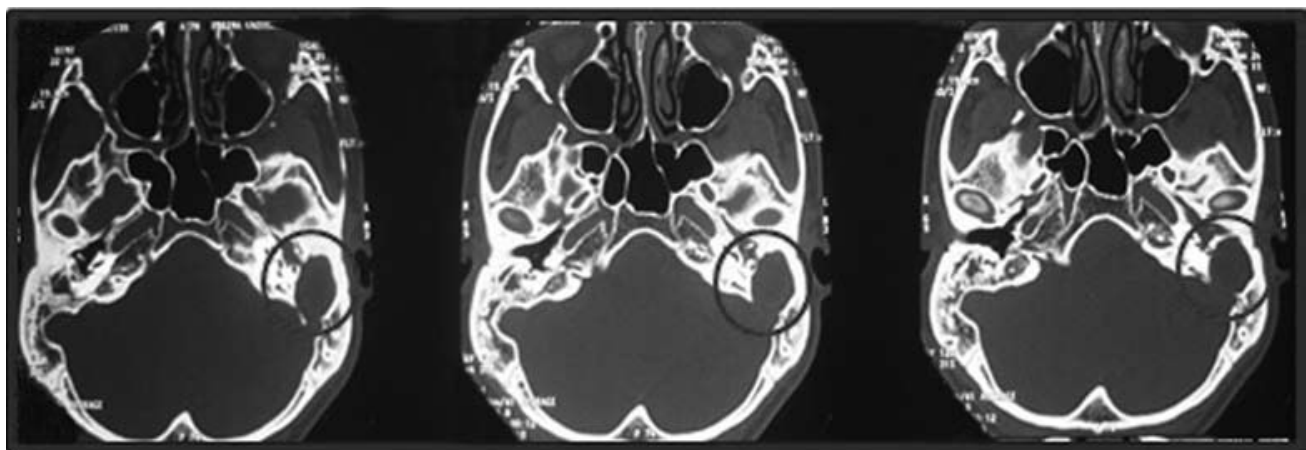

Figure 1. Temporal bone CT scan, axial section at the level of the superior semicircular canals showing a large cholesteatoma on the left with destruction of the posterior wall of the mastoid and extension into the posterior cranial fossa.
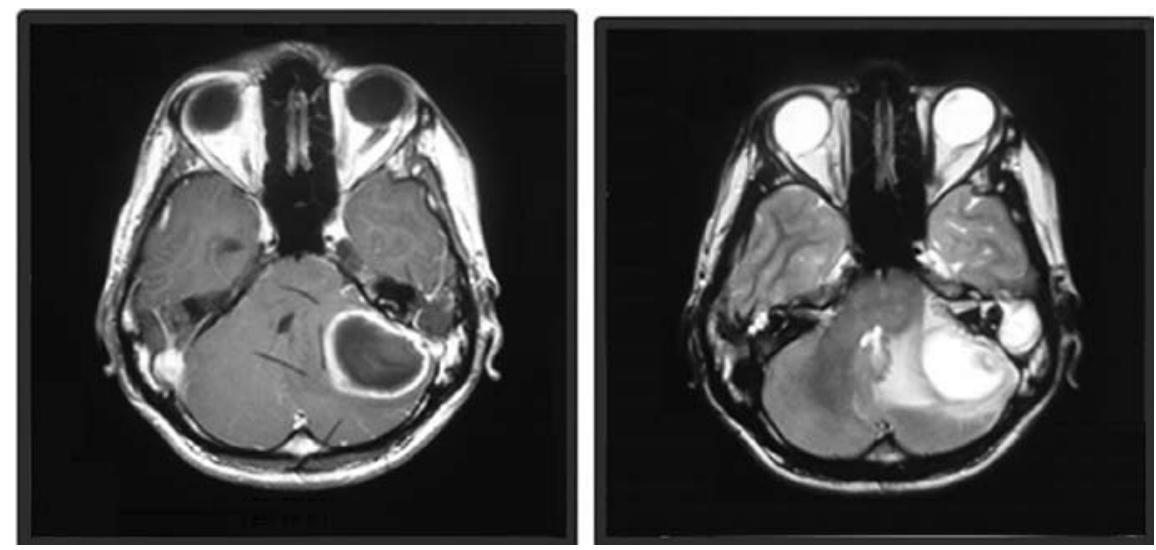

Figure 2. Brain MRI axial section at the level of the superior semicircular canals showing a large rim enhancing mass involving the periphery of the left cerebellar hemisphere measuring approximately $3.3 \mathrm{~cm} \times 4.1 \mathrm{~cm} \times 2.6 \mathrm{~cm}$ in AP, transverse and craniocaudal dimensions.

On the day of admission, he now had severe headache, dizziness and occasional vomiting. No neurologic symptoms such as facial asymmetry, lagopthalmos, or paresthesias were reported. A cerebellar abscess was entertained. On the second hospital day, the patient's neurologic status started to deteriorate with moments of agitation and combative behavior interspersed with drowsiness and lucid behavior. His blood pressure also started to increase from $110 / 80$ on admission to 160/110. Magnetic Resonance Imaging (MRI) revealed a rim-enhancing destructive lesion in the left mastoid and a left cerebellar abscess. (Figure 2)

On the third hospital day, he showed signs of neurologic deterioration despite aggressive medical management, but we opted to continue temporizing rather than risk worsening the situation by performing mastoidectomy alone without the availability of the neurosurgery service. On the fifth hospital day, emergency burr holes with left lateral occipital craniectomy and aspiration of abscess was performed with radical mastoidectomy and meatoplasty, AS. He was discharged improved on the $9^{\text {th }}$ hospital day ( $4^{\text {th }}$ post-operative day).

\section{DISCUSSION}

A common dictum in our institution about the management of chronic suppurative otitis media (CSOM) with extra- or intra- cranial complications is, 'never let the sun set without performing ear surgery on the patient.' Our patient presented at the emergency room with warning signs of an intracranial extension of the ear infection. The frequent headaches and vomiting probably indicated an increase in intracranial pressure.

The patient's deteriorating neurologic status with moments of agitation and combative behavior interspersed with drowsiness and lucid behavior and increasing blood pressure by the second hospital day were further signs of increased intracranial pressure. A cerebellar abscess was confirmed on MRI.

Deciding that the risks of herniation and further damage were far greater than potential benefits of performing mastoidectomy alone without aspiration of the cerebellar abscess, we opted to wait until simultaneous left lateral occipital craniectomy and aspiration of abscess could be performed with the mastoidectomy and meatoplasty.

A review of the literature shows authors advocating neurosurgery 


\section{FEATURED GRAND ROUNDS}

first then performing ear surgery after the patient has been stabilized. This has been emphasized time and again by Shaw and Russel. ${ }^{2}$

Through the years, the practice has slowly shifted to performing simultaneous neurosurgery and mastoidectomy. Richter et al. ${ }^{3}$ reported a case of a 39-year-old male diagnosed with otogenic cerebellar abscess surgically managed by performing craniectomy and mastoidectomy together. Other physicians also reported favorable outcomes for concomitant craniectomy and mastoidectomy, including Garayev et al. ${ }^{4}$ and Kurien et al. ${ }^{5}$

Another shift in surgical practice advocates evacuation of the brain abscess via a transtemporal approach. Penido Nde et al. ${ }^{6}$ reported favorable results for 10 patients in whom the brain abscess was drained through open mastoidectomy out of 33 patients with otogenic brain abscess over 15 years. In 2010, Alaani et al. 7 reported a series of seven patients where a transtemporal approach to otogenic brain abscess was employed. In all cases, the abscess and ear pathology were successfully treated using a single-stage transmastoid approach. These experiences all show that mastoidectomy and drainage of brain abscess could be done safely together with little risk.

In the overall management of patients it is also wise to consider the economic aspects of treating disease. If shorter hospital stays can be attained by alternative methods with the same favorable outcomes as gained by usual practices, it may be time to consider new management approaches. The benefits of waiting for a neurosurgeon versus the risks of evacuating the abscess through a transtemporal approach should be weighed in emergent situations. Based on the current literature, a transtemporal approach to the evacuation of a brain abscess can be performed in the absence of a neurosurgeon but prudence would dictate that a neurosurgical evaluation should be undertaken if readily available.

1. Thomas LE, Goldstein JN. 2010. Brain abscess in emergency medicine. Medscape Reference [homepage on the internet] c1994-2012 [updated 2010 May 13; cited 2012 Sept.12]. Available from: http://emedicine.medscape.com/article/781021-overview\#showall.

2. Shaw MD, Russel JA. Cerebellar abscess. A review of 47 cases. J Neurol, Neurosurg, Psychiatry. 1975 May,38(5):429-435.

3. Richter GT, Smith JA, Dornhoffer JL. Otogenic cerebellar abscess: a case report. Ear Nose Throat J. 2009 Apr;88(4):E25-28.

4. Garayev A, Talyshinskiy A, Büntzel J. [Otogenic cerebellar abscess: Two case histories]. [article in German]. Laryngorhinootologie 2007 Sep;86(9):660-663. Epub 2007 Jan 11. [abstract cited 2012 Sept 2] Available from: http://www.ncbi.nlm.nih.gov/pubmed/17219339.

5. Kurien M, Job A, Matthew J, Chandy M. Otogenic intracranial abscess: concurrent craniotomy and mastoidectomy- changing trends in a developing country. Arch Otolaryngol Head Neck Surg. 1998 Dec;124(12):1353-1356.

6. Penido Nde O, Borin A, Iha LC, Suguri VM, Onishi E, Fukuda Y, Cruz OL. Intracranial complications of otitis media: 15 years of experience in 33 patients. Otolaryngol Head Neck Surg. 2005 Jan;132(1):37-42.

7. Alaani A, Coulson C, McDermott AL, Irving RM. Transtemporal approach to otogenic brain abscesses. Acta Otolaryngol. 2010 Nov;130(11):1214-1219.
} 